\section{Neurro \\ endocrinology}

Ahlman, H. 67

Åkerström, G. 62

Annibale, B. 16

Arnold, C. 39, 102 (A)

Arnold, C.N. 101 (A)

Arnold, R. 101, 102 (A)

Babinska, A. 103 (A)

Blum, H.E. 101 (A)

Blumstein, N.M. 100 (A)

Böhm, B.O. 100 (A)

Capurso, G. 16

Cichocki, A. 101 (A)

Corcos, O. 79

Cybulla, M. 39

Delle Fave, G. 16

Detjen, K. 85

Duddy, J. 100 (A)

Franke, W.W. 99 (A)

Göke, R. 102 (A)

Grabowski, P. 102 (A)

Griss, S. 102 (A)

Grötzinger, C. 8

Guzel, Z. 101 (A)

Heine, B. 102 (A)
$(\mathrm{A})=$ Abstracts
Hellman, P. 62

Hentic, O. 79

Herder, W.W. de 20

Hessman, O. 62

Hoersch, D. 102 (A)

Hofmann, I. 99 (A)

Horst-Schrivers, A.N.A. van der 28

Jaskiewicz, K. 103 (A)

Jensen, R.T. 23

Jeziorski, K. 101 (A)

Kaltsas, G. 100 (A)

Karges, W. 100 (A)

Kema, I.P. 28

Klöppel, G. 12

Kontogeorgos, G. 100 (A)

Krolicki, L. 101 (A)

Kvols, L. 33

Langbein, L. 99 (A)

Limouris, G. 100 (A)

Ling, H. 39

Links, T.P. 28

Lorf, T. 102 (A)

Makras, P. 100 (A)

McGowan, G. 100 (A)
Mottaghy, F.M. 100 (A)

Nalecz, A. 103 (A)

Nasierowska-Guttmejer, A. 101 (A)

Neumann, H.P.H. 39

Nilsson, O. 67

Öberg, K. 57

Olausson, M. 67

O'Shea, D. 100 (A)

Osmak, L. 62

O'Toole, D. 74, 79

Panzuto, F. 16

Papadogias, D. 100 (A)

Pape, U.F. 99 (A)

Pape, U.-F. 94

Piaditis, G. 100 (A)

Plöckinger, U. 35, 99 (A)

Powell, D. 100 (A)

Prätzel, S. 99 (A)

Raddatz, D. 102 (A)

Ramadori, G. 102 (A)

Reske, S.N. 100 (A)

Reubi, J.C. 51

Rindi, G. 12

Roschmann, N. 100 (A)
Rosewicz, S. 85

Roszkowska, K. 101 (A)

Ruszniewski, P. 74, 79

Rzepko, R. 103 (A)

Schaefer, O. 39

Scherübl, H. 102 (A)

Schmid, H.A. 47

Schoeffter, P. 47

Scholz, A. 85

Schories, M. 39

Schwörer, H. 102 (A)

Sosnowski, A. 101 (A)

Stein, H. 102 (A)

Taal, B.G. 3

Toth, E. 99 (A)

Visser, O. 3

von Marschall, Z. 85

Vries, E.G.E. de 28

Wiedenmann, B. 1, 35, 94, 99 (A)

Willemse, P.H.B. 28

Wymenga, A.N.M. 28

Zeitz, M. 102 (A)

\title{
Subject Index Vol. 80, Suppl. 1, 2004
}

Ablative therapies 74

Acromegaly 47

Angiogenesis 85

Appendix 33

Atrophic body gastritis 16

Basic and clinical research 94

Bombesin 51

Carcinoid 8, 16, 47, 67

- $\quad$ syndrome 28

- tumors 28, 33

Chemoembolization 74

Chemotherapy 79

Cholecystokinin 51

Classification 35

Complications 28

C-peptide 20

Cytotoxic coupled somatostatin analogue 57
Diagnosis 35

Embolization 67

Endocrine cells 12

- pancreatic tumours 62

- tumors 12,20

Epidemiology 3, 35

Gastric carcinoid 16

Gastrin 16

Gastrinomas 23

Gastroenteropancreatic endocrine tumors 74,79

- neuroendocrine tumors 8, 39

Genetics 12

Glucagon-like peptide 151

Growth factor 8

Gut 12

Helical computer tomography 35

Hemicolectomy 33
Hormones 12

Immunohistochemistry 12

Insulin 20

Insulinoma 20

Interferon- $\alpha 85$

Liver metastases 74

Liver transplantation 67

Multiple endocrine neoplasia 16

- _ _ type 162

Neuroendocrine markers 12

- tumor disease 85

- tumors 3,16,35, 47, 94

New drugs 94

Pancreas 12,20

Peptide receptor targeting 51

PET 35

Poorly differentiated tumours 79

Proliferation 8
Radiofrequency ablation 74 Receptor autoradiography 51

- co-expression 51

Regulatory peptides 51

SOM230 47, 57

Somatostatin 47, 51

- receptor scintigraphy 23,35

Surgical treatment 62

Tumour biology 8

- reduction 67

Ultra-high-dose treatment 57

Unresolved clinical issues 94

Vasoactive intestinal peptide 51

Von Hippel-Lindau disease 39

Well-differentiated tumours 79

Zollinger-Ellison syndrome 23

\section{KARGER}

(C) 2004 S. Karger AG, Basel

Fax +41613061234

E-Mail karger@karger.ch

www. karger.com
Accessible online at:

www.karger.com/nen 